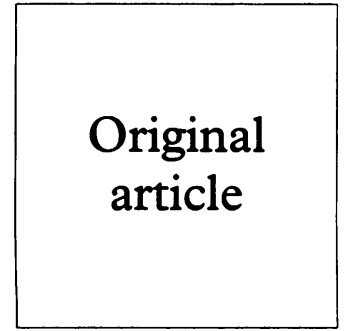

\title{
Surveillance of antibiotic resistance in Neisseria gonorrhoeae in the Netherlands, 1977-95
}

$M \mathrm{~J}$ W van de Laar, Y T H P van Duynhoven, $M$ Dessens, $M$ van Santen, $B$ van Klingeren

Objective: To evaluate the prevalence and epidemiology of penicillinase producing Neisseria gonorrhoeae (PPNG) and tetracycline resistant $N$ gonorrhoeae (TRNG) in the period 1977-95 in the Netherlands. To compare auxotypes, serovars, and antibiograms of PPNG, non-PPNG, and TRNG. To identify determinants in patient characteristics for the epidemic spread of TRNG/PPNG.

Methods: With respect to the national gonococcal surveillance all PPNG isolates from 30 laboratories over the country in 1977-90 and all gonococcal isolates from five sentinel laboratories (during 1 month per quarter) in 1991-5 were collected. Isolates were auxotyped and serotyped, the susceptibility for various antibiotics was tested and plasmid contents were evaluated. Additional data on PPNG infected individuals were collected retrospectively during a microepidemic of TRNG/PPNG. Univariate and multivariate analyses were performed to identify risk factors for TRNG/PPNG infections.

Results: In 1995 an overall high prevalence of PPNG infection (27\%) and TRNG among PPNG infection (24\%) was found in the Netherlands. Importantly, PPNG were found to have higher MICs for ceftriaxone and ciprofloxacin than non-PPNG; clinically relevant resistance to these antibiotics (or related agents) may emerge first among these strains. The observed diversity of strains (123 auxo/serovar classes since 1988) indicates a continuous introduction of new strains into the community. The epidemic increase of TRNG/PPNG was mainly caused by A/S classes NR/1B-6, PRO/1A-3, and PRO/1A-6, suggesting a clonal spread of a few strains; the rapid spread was associated with transmission in high risk individuals (that is, prostitutes and their clients).

Conclusion: The prevalence of PPNG in the Netherlands remains high and reduced sensitivity to other antimicrobials was detected among the PPNG strains. This underlines the necessity for a continuous national surveillance of resistance in gonococci including limited epidemiological information.

(Genitourin Med 1997;73:510-517)

Keywords: Neisseria gonorrhoeae; antibiotic resistance; surveillance programme

\section{Introduction}

In 1976 the first strains of Neisseria gonorrhoeae were isolated with complete resistance to penicillin through the production of $\beta$ lactamase. ${ }^{1-3}$ These strains occurred almost simultaneously in many parts of the world and penicillinase producing $N$ gonorrhoeae (PPNG) have become endemic since then with large geographical variations. Alternative therapy for gonorrhoea became a necessity in many communities. ${ }^{4-10}$ Penicillin is only recommended if local surveillance resistance patterns indicate that resistance is low $(<5 \%)$. At present, spectinomycin, cephalosporins, and the newer fluoroquinolones remain effective for gonorrhoea therapy. ${ }^{8-11}$ High level plasmid mediated tetracycline resistant $N$ gonorrhoeae (TRNG) was first observed in the United States in $1985^{71213}$ and is now spreading worldwide. Although tetracyclines are not recommended as the sole therapy for gonorrhoea (and would only be effective in a multidose regimen), they are widely used in some developing countries. The use of tetracyclines for treatment of other STDs, such as Chlamydia trachomatis genital tract infection and non-specific urethritis, may have encouraged the selection of tetracycline resistant strains within Europe and the United States. ${ }^{1415}$

Antibiotic resistance in gonococci has been monitored in the Netherlands since penicillinase producing strains of $N$ gonorrhoeae were first reported, in 1976. Among the PPNG isolates in the Netherlands in 1985, 12 strains were found with high level resistance to tetracycline. ${ }^{16}$ All these strains contained the $25 \cdot 2$ megadalton plasmid. ${ }^{17}{ }^{18}$ In 1988 , an increase was observed of tetracycline resistant strains among PPNG isolates (9\%) reaching a peak in $1989(40 \%) .{ }^{14}$ The epidemic increase of TRNG/PPNG was suggested to be related to the introduction and clonal spread of a limited number of resistant strains. ${ }^{14}$ Little is known about factors that contribute to the introduction of antibiotic resistant gonococci. It has been suggested that individuals who introduce resistant gonococci may differ from the individuals who subsequently become infected and contribute to the establishment of these organisms in the community. ${ }^{19} 20$

In this report, we evaluate the prevalence and epidemiology of PPNG and TRNG infections in the Netherlands in the period 1977-95, the current status of antibiotic resis- 
tance in $N$ gonorrhoeae, and the nature of the microepidemic of TRNG/PPNG. Two sources of gonococcal data were used: the National PPNG Surveillance Programme and an additional survey on the microepidemic of TRNG/PPNG. The surveillance data were used to describe trends in PPNG and PPNG/TRNG infections, trends in resistance to other clinically relevant antibiotics and in microbiological characteristics, whereas the more detailed survey enlightened the characteristics of the population in which the TRNG/PPNG have spread. Finally, the results were used to briefly review the appropriateness of the current gonococcal surveillance programme.

\section{Patients and methods}

NATIONAL PPNG SURVEILLANCE PROGRAMME Period 1977-90

During the period 1977 to 1990 almost all (90-95\%) PPNG isolates were sent to the National Institute of Public Health and the Environment (RIVM) for quantitative susceptibility testing, auxotyping, serotyping, and plasmid characterisation. The prevalence of PPNG was calculated based on the annual inquiries among the participating laboratories on the total number of gonococcal isolates (which more or less agreed with the number of notified cases) and the number of $\beta$ lactamase producing strains. The prevalence of TRNG was based on the annual number of gonococcal isolates tested for their susceptibility to tetracycline. Minimum inhibitory concentrations (MIC) were determined for clinically relevant antibiotics-penicillin, tetracycline, erythromycin, spectinomycin, ciprofloxacin, and ceftriaxone. The method was as described earlier, using Isosensitest agar supplemented with $5 \%$ horse blood and multipoint inoculation. ${ }^{21} 22$ The nutritional requirements for growth (auxotyping) were determined routinely since the early 1980s using the defined media and method of Hendry and Stewart ${ }^{23}$ with slight modifications as described previously. ${ }^{24}$ Serotyping with a panel of 12 monoclonal antibodies to gonococcal outer membrane protein I (Syva Co, CA, USA) was introduced in 1987 using the nomenclature according to Knapp et al. ${ }^{25}$ Auxotyping alone yields very limited data for the epidemiology of gonorrhoea since the majority of strains belong to two auxotypesthat is, non-requiring (NR) and proline requiring (PRO) strains. However, combinations with serovar patterns enables us to perform highly discriminative gonococcal typing into auxotype/serovar (A/S) classes. ${ }^{26}$ Within the framework of the National PPNG Surveillance Programme limited epidemiological data were collected. A short form that included information on the patient (sex, age, nationality, sexual orientation, commercial sex, history of gonorrhoea, geographic location of infective contact, date of isolation) and a laboratory identification number, was sent by the laboratory along with the PPNG isolate. Unfortunately, many records were incomplete because the required information was not available at the laboratory.
Period 1991-5

In 1991 the National PPNG Surveillance Programme was modified into a sentinel surveillance: all gonococcal (both PPNG and non-PPNG) isolates from five sentinel laboratories in three large cities, accounting for about $70 \%$ of total PPNG in preceding years, were collected for MIC determination and microbiological typing for 1 month quarterly (March, June, September, and December of each year). In 1994 the surveillance programme on resistance in gonococci was changed again: the auxotyping and serotyping of isolates were no longer performed and also the national annual inquiries on the number of ( $\beta$ lactamase producing) gonococcal strains were discontinued. Hence, from 1994 onwards, the National PPNG Surveillance Programme became restricted to quantitative susceptibility testing of a sample of gonococcal (both PPNG and non-PPNG) isolates from five sentinel laboratories.

MICROEPIDEMIC OF TRNG/PPNG Additional data collection

PPNG isolates strains from five main laboratories in Amsterdam, Rotterdam, The Hague in 1989 and 1990 were included in this study: auxotyping, serotyping, distribution of MIC for tetracycline. PPNG isolates were defined as TRNG/PPNG if they had a tetracycline MIC of $\geqslant 16 \mathrm{mg} / \mathrm{l}$. From the routine database characteristics were available as described above. Because of incomplete records, additional epidemiological information was collected retrospectively: the laboratory was asked to reveal the treating physician by linking the laboratory identification number with their own code. Then the physician was asked to fill in a short questionnaire, including the same characteristics on the patient by retrospective case note review. Details of the study design have been reported previously. ${ }^{27}$

\section{Statistical analysis}

To assess determinants of tetracycline resistance, patients infected with TRNG/PPNG were compared with those infected with nonTRNG/PPNG strains. In univariate analyses, associations between variables were examined using $\chi^{2}$ and Fisher's exact tests. Crude odds ratios (ORs) and their 95\% confidence intervals (CIs) were calculated for the association between TRNG/PPNG infection and statistically significant variables $(p<0.05)$. Multivariate logistic regression analysis was used to adjust for confounding variables with resistance to tetracycline as the outcome variable. All analyses were performed separately for men and women.

\section{Results}

NATIONAL PPNG SURVEILLANCE PROGRAMME PPNG and TRNG prevalence

From 1984 onwards, the incidence of notified cases of gonorrhoea dropped dramatically in the Netherlands. Between 1981 and 1988, an almost fivefold decrease in the gonorrhoea incidence rate was observed: from 104 to 23 


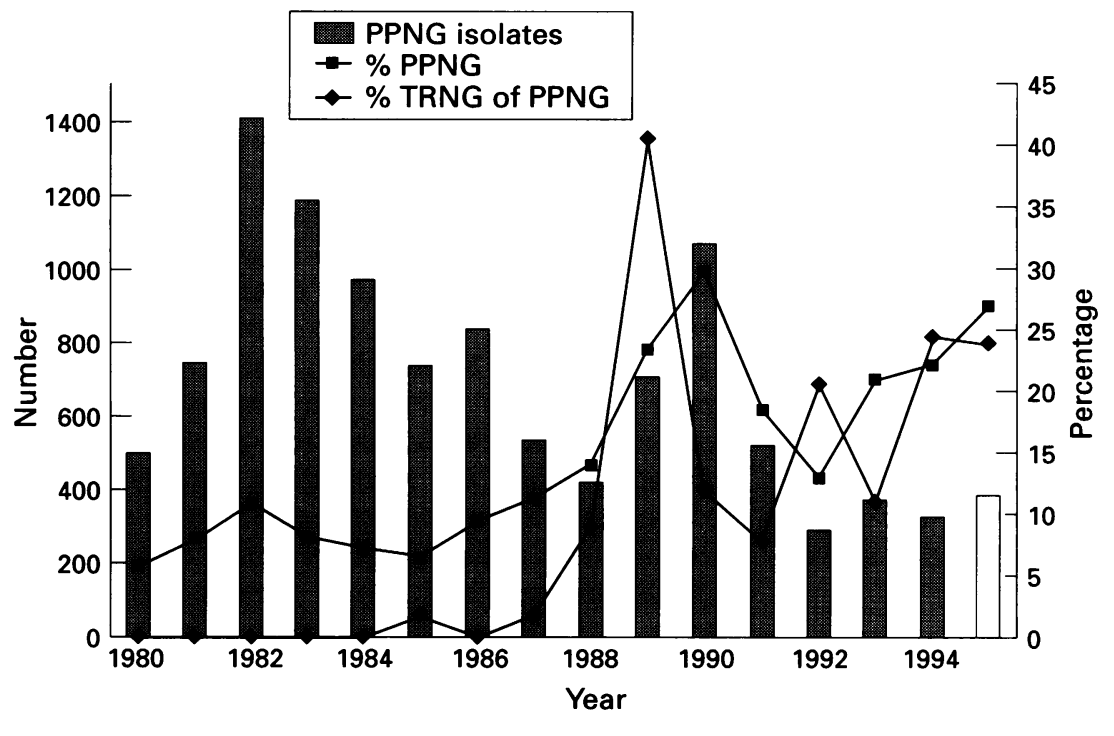

Figure 1 Number of PPNG isolates, prevalence of PPNG (as proportion of reported gonococcal isolates), and tetracycline resistance (TRNG) as proportion of PPNG isolates in the Netherlands, National PPNG Surveillance Programme, 1980-95.

cases per 100000 population. Since 1988 , the sharp decline levelled off and the incidence was approximately nine per 100000 in 1994 and 1995. The absolute number of PPNG cases in the Netherlands showed a declining trend as well (fig 1). Between 1982 and 1988 the number of PPNG decreased by $70 \%$, in 1989 and 1990 the number more than doubled and in 1991 it decreased sharply again. Since then the number of PPNG cases remained constant between 300 and 400 cases per year. However, the proportion of PPNG among gonococcal isolates showed an upward trend. PPNG accounted for $11 \%$ of total reported cases in 1982, increased to a maximum of $30 \%$ in 1990 , and then persisted at an endemic level of $20-30 \%$ of all cases.

In 1988, among the PPNG isolates, an increase was observed of high level tetracycline resistant strains (TRNG). In 1989 the TRNG epidemic reached a peak with $40 \%$ of the PPNG isolates being tetracycline resistant (see fig 1) with large geographical variation between cities. Since then the prevalence of TRNG among PPNG decreased to $8 \%$ in 1991 but had increased again in recent years (1995: 24\%).

\section{Auxotype serovar}

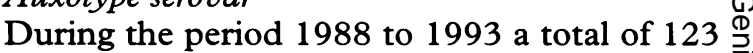
auxotype/serovar (A/S) classes was found, with a predominance of NR/IB-1 and NR/IB-3 which were present throughout, in varying 3 percentages (table 1). Specific A/S classes $\stackrel{\circ}{\circ}$ were found for various types of plasmid mediated resistance: NR/IB-6, PRO/IA-3, and $\stackrel{5}{+}$ PRO/IA-6 among PPNG/TRNG, NR/IB-2 을 among non-PPNG/non-TRNG, and NR/IB- $6 \frac{\bar{\sigma}}{\overline{0}}$ among non-PPNG/TRNG. Transient A/S classes were often found, contributing highly to the distribution in a particular year and disappearing thereafter-that is, NR/IA-3, $\vec{\circ}$ NR/IA-4, PRO/IB-1, PRO/IB-3 among non- $\overrightarrow{\vec{H}}$ PPNG/TRNG and NR/IB-19 and NR/IB-22 for PPNG/non-TRNG.

\section{PPNG/TRNG isolates}

Since 1991, all gonococcal isolates from five $i$ sentinel laboratories (collected 1 month quarterly) were tested to monitor resistance in gonococci. Overall, $26 \cdot 2 \%$ of isolates collected $\overrightarrow{0}$ in the period 1991 to $1995(n=1702)$ were resistant to penicillin, tetracycline, or both (fig $\frac{\mathbb{N}}{3}$ 2). High level resistance to tetracycline has increased between 1991 and 1995, both in PPNG and non-PPNG isolates. The percentage of TRNG among PPNG remains high between $20-25 \%$ and the percentage of TRNG among non-PPNG isolates has increased consistently (1995: 15\%). Combined resistance TRNG/PPNG is found in $6 \%$ of all gonococcal isolates (not in figure).

Distribution of MICs

The distribution of ceftriaxone MICs was shifted to the right (that is, decreased susceptibility) for PPNG isolates compared with nonPPNG isolates (fig 3). This was also found for 3 ciprofloxacin, although the difference was less $\dot{\delta}$ pronounced. Since 1993, three strains were

Table 1 Diversity of auxotype/serovar classes (in percentages of annual number of isolates) among PPNG/non-TRNG, PPNG/TRNG, non-PPNG/TRNG and non-PPNG/non-TRNG isolates, National PPNG Surveillance Programme, $1988-93^{*} . A / S$ classes are shown if they represent at least $5 \%$ of total isolates in one of the presented years

\begin{tabular}{|c|c|c|c|c|c|c|c|c|c|c|c|c|c|c|c|}
\hline \multirow[b]{2}{*}{ Isolates } & \multicolumn{6}{|c|}{ PPNG/non-TRNG } & \multicolumn{3}{|c|}{ PPNG/TRNG† } & \multicolumn{3}{|c|}{ non-PPNG/non-TRNG } & \multicolumn{3}{|c|}{ non-PPNG/TRNG } \\
\hline & $\begin{array}{r}1988 \\
378\end{array}$ & $\begin{array}{r}1989 \\
409\end{array}$ & $\begin{array}{r}1990 \\
939\end{array}$ & $\begin{array}{r}1991 \\
95\end{array}$ & $\begin{array}{r}1992 \\
42\end{array}$ & $\begin{array}{r}1993 \\
63\end{array}$ & $\begin{array}{r}1988 \\
38\end{array}$ & $\begin{array}{r}1989 \\
280\end{array}$ & $\begin{array}{r}1990 \\
141\end{array}$ & $\begin{array}{r}1991 \\
405\end{array}$ & $\begin{array}{r}1992 \\
355\end{array}$ & $\begin{array}{r}1993 \\
182\end{array}$ & $\begin{array}{r}1991 \\
26\end{array}$ & $\begin{array}{r}1992 \\
23\end{array}$ & $\begin{array}{r}1993 \\
18\end{array}$ \\
\hline NR/1B-1 & 15 & 17 & 54 & 46 & 21 & 2 & 13 & 2 & 26 & 21 & 9 & 10 & 12 & 4 & \\
\hline $\mathrm{NR} / 1 \mathrm{~B}-3$ & 42 & 36 & 12 & 15 & 7 & 19 & 26 & 10 & 3 & 10 & 5 & 14 & 15 & 4 & 11 \\
\hline $\mathrm{NR} / 1 \mathrm{~B}-6$ & & 3 & 2 & & & 11 & 26 & 46 & 11 & 2 & 4 & 3 & 46 & 13 & \\
\hline $\begin{array}{l}\text { NR/1B-2 } \\
\text { NR/1B-19 }\end{array}$ & & & 2 & 5 & 5 & & & & & 20 & 19 & 11 & 4 & & \\
\hline NR/1B-22 & & & & & & 27 & & & & & & & & & \\
\hline $\mathrm{NR} / 1 \mathrm{~A}-3$ & 2 & 2 & & & 7 & & & & & & 4 & & 8 & 17 & \\
\hline$N R / 1 A-4$ & 2 & & & & & 5 & & & & & 5 & & & 13 & 6 \\
\hline NR/1A-6 & 2 & & 2 & 5 & 7 & & & & 4 & & & & 4 & & \\
\hline NR/1A-8 & & & & & 7 & 11 & & & & & & 4 & & & \\
\hline PRO/1A-3 & & 1 & 1 & & & & 26 & 19 & 4 & & 4 & & 4 & 9 & \\
\hline $\mathrm{PRO} / 1 \mathrm{~A}-6$ & 2 & 1 & 2 & & & & & 14 & 31 & & & & & & 6 \\
\hline PRO/1B-1 & 2 & 2 & & 2 & & 8 & & & & & & & & & 17 \\
\hline $\mathrm{PRO} / 1 \mathrm{~B}-3$ & & 1 & & & & & & & & & & 4 & 4 & & 22 \\
\hline PRO/1B-7 & & & & & & & & & & & 7 & 9 & & & \\
\hline other classes & 29 & 33 & 24 & 26 & 36 & 17 & 8 & 9 & 17 & 47 & 50 & 53 & 7 & 40 & 38 \\
\hline
\end{tabular}

^1988-90: A/S classes for all PPNG/non-TRNG and PPNG/TRNG isolates obtained from 30 participating laboratories nationwide. 1991-3: A/S classes for PPNG/non-TRNG, PPNG/TRNG, non-PPNG/TRNG, non-TRNG/non-PPNG isolate obtained from five sentinel laboratories (1 month per quarter).

†In 1991-3 the number of PPNG/TRNG isolates was too low to present in table with 8, 11 and 10 isolates with 6,8 , and 6 auxo/serovar classes, respectively. 


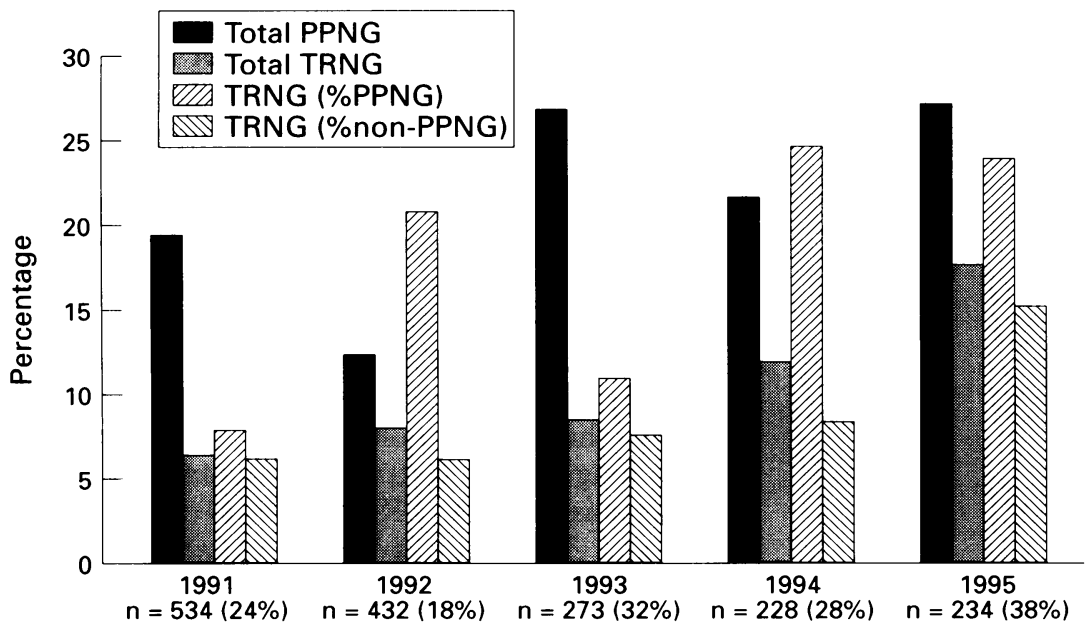

Figure 2 Resistance to Neisseria gonorrhoeae in the Netherlands, National PPNG Surveillance Programme, 1991-5: PPNG and TRNG as proportion of total number of isolates and TRNG as proportion of total number of PPNG and non-PPNG isolates. The annual number of gonococcal isolates and overall percentage of resistance (PPNG-TRNG) is presented on the $x$ axis per year.
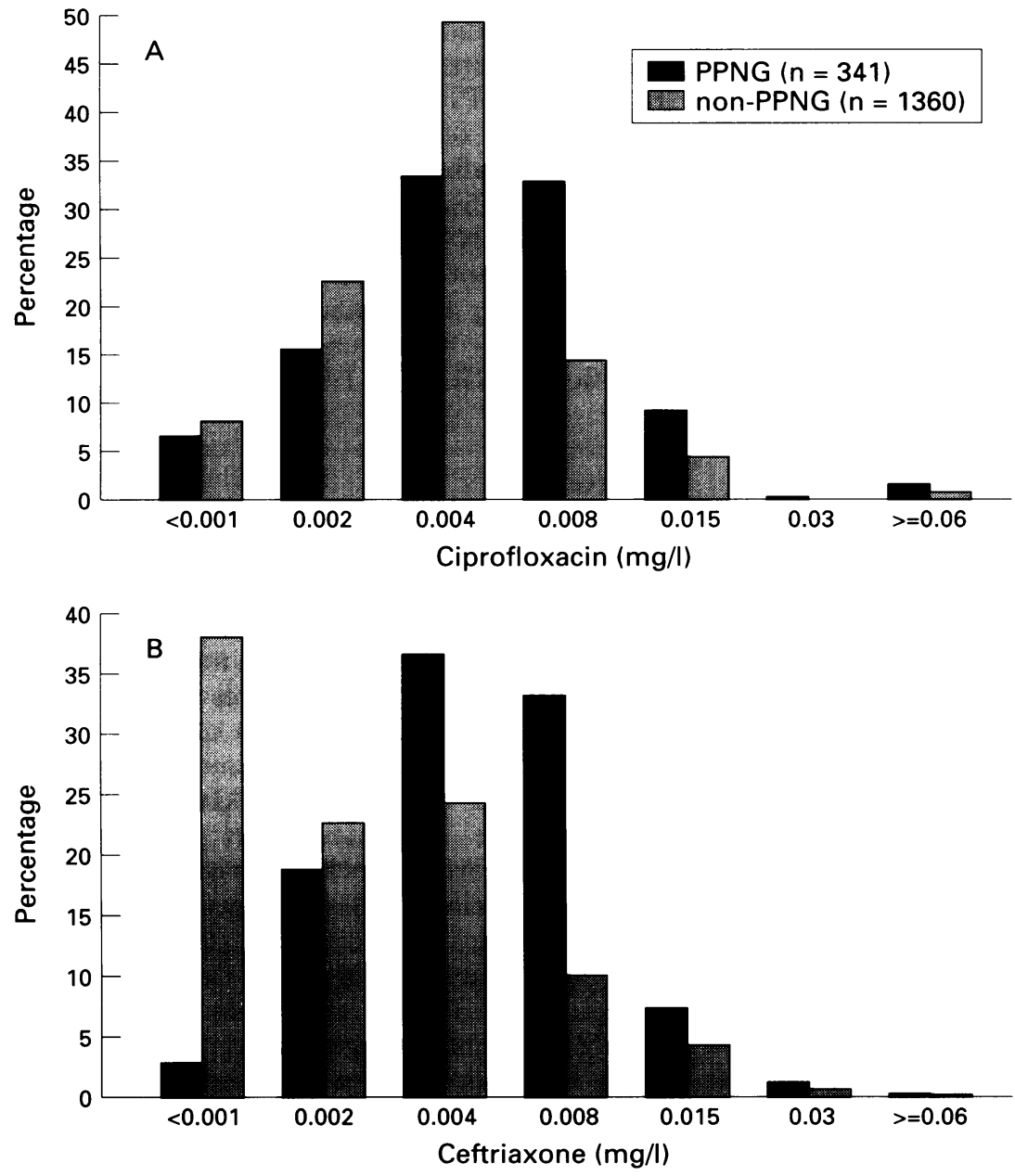

Figure 3 MIC distributions for ciprofloxacin $(A)$ and ceftriaxone (B) for PPNG and non-PPNG isolates, National PPNG Surveillance Programme, 1991-5.

Table 2 Temporal distribution of auxotype/serovar classes during a microepidemic of TRNG/PPNG, National PPNG Surveillance Programme, the Netherlands, 1989-90 (in percentages of total number of TRNG per quarter)

\begin{tabular}{|c|c|c|c|c|c|c|c|c|}
\hline & \multicolumn{4}{|c|}{1989} & \multicolumn{4}{|c|}{1990} \\
\hline & $1 s t$ & $2 n d$ & $3 r d$ & $4 t h$ & $1 s t$ & $2 n d$ & $3 r d$ & $4 t h$ \\
\hline TRNG/PPNG per quarter & 52 & 51 & 68 & 49 & 17 & 8 & 44 & 22 \\
\hline NR/IB-1 $(n=29)$ & 0 & 0 & 2 & 4 & 18 & 50 & 23 & 41 \\
\hline NR/IB-6 $(n=108)$ & 81 & 45 & 25 & 33 & 47 & 13 & 0 & 0 \\
\hline $\mathrm{PRO} / \mathrm{IA}-3(\mathrm{n}=51)$ & 12 & 37 & 6 & 39 & 12 & 0 & 2 & 0 \\
\hline PRO/IA-6 $(\mathrm{n}=70)$ & 0 & 0 & 50 & 8 & 18 & 25 & 50 & 23 \\
\hline Other A/S class $(n=82)$ & 7 & 18 & 17 & 16 & 5 & 12 & 25 & 36 \\
\hline
\end{tabular}

found that were not inhibited by $0.03 \mathrm{mg} / \mathrm{l} \mathrm{cef}-$ triaxone (two non-PPNG $(1 \cdot 1 \%$ ), one PPNG $(1.6 \%))$. On the other hand, 18 strains (six PPNG $(1.8 \%)$ and 12 non-PPNG $(0.9 \%))$ were not inhibited by $0.03 \mathrm{mg} / 1$ ciprofloxacin; the highest MIC was $1 \mathrm{mg} / \mathrm{l}$ found for one PPNG isolate.

\section{MICROEPIDEMIC OF TRNG/PPNG \\ TRNG prevalence}

To investigate the increase of tetracycline resistance 1257 PPNG isolates from five main laboratories, participating in the National PPNG Surveillance Programme, were included in the additional survey. Eighty three per cent (1047/1257) of the questionnaires were returned with epidemiological information on the patients. Together with the routinely collected information, 1185/1257 (94.3\%) PPNG isolates were available for analyses-that is, 472 in 1989 and 713 in 1990. In 1989 almost half of PPNG was also TRNG $(\mathrm{n}=220 ; 47 \%)$; in $199013 \%(\mathrm{n}=$ $91 ; \mathrm{p}<0.001)$. The prevalence of TRNG/ PPNG varied in time and region: the prevalence of TRNG/PPNG reached a peak in the second and third quarter of 1989 and the highest prevalence was found in The Hague $(>80 \%$ in the first and second quarter of 1989).

\section{Auxotype serovar}

The most prevalent A/S classes among the non-TRNG/PPNG strains $(\mathrm{n}=874)$ were NR/IB-1 (45\%) and NR/IB-3 (20\%). For the TRNG/PPNG isolates $(n=311)$, these A/S classes were rarely found; NR/IB-6 (34\%), PRO/IA-3 (16\%), and PRO/IA-6 (23\%) dominated. Otherwise, high level resistance to tetracycline in the latter $\mathrm{A} / \mathrm{S}$ classes ranged between $81 \%$ and $91 \%$. The percentage of combined resistance (TRNG/PPNG) among other common $\mathrm{A} / \mathrm{S}$ classes was much lower, with a maximum of $15 \%$. There were also marked differences in the temporal distribution of A/S classes among TRNG/PPNG isolates (table 2): NR/IB-6 was highly prevalent in the first 6 months of 1989 and disappeared in 1990 whereas NR/IB-1 and PRO/IA-6 were mainly responsible for TRNG/PPNG in the second half of 1990 .

\section{Demography of patients}

TRNG/PPNG infections were more common in men than in women - that is, $49 \%$ of PPNG infections in men in 1989 were also tetracycline resistant compared with $36 \%$ of PPNG in women $(p=0.02)$. In 1990 this difference between both sexes disappeared (men $12 \%$; women $16 \%$ ). Table 3 shows that the percentage TRNG/PPNG differed per city per year: in 1989 TRNG/PPNG mainly came from The Hague and Rotterdam. In 1989 TRNG/ PPNG infections were more often found among patients of Turkish nationality than in 1990. The percentage of patients reporting commercial sex work (CSW) contacts was highest for TRNG/PPNG infections in 1989 but the information was missing for $30 \%$ of the patients (men 25\%; women $46 \%$ ). For 
Table 3 Characteristics of 1185 patients diagnosed with PPNG in 1989 and 1990 with respect to resistance to tetracycline (TRNG), survey in five laboratories participating in the National PPNG Surveillance Programme, the Netherlands

\begin{tabular}{|c|c|c|c|c|}
\hline & \multicolumn{2}{|l|}{1989} & \multicolumn{2}{|l|}{1990} \\
\hline & $\begin{array}{l}\text { non-TRNG } \\
(n=252)\end{array}$ & $\begin{array}{l}T R N G \\
(n=220)\end{array}$ & $\begin{array}{l}\text { non-TRNG } \\
(n=622)\end{array}$ & $\begin{array}{l}T R N G \\
(n=91)\end{array}$ \\
\hline \multicolumn{5}{|l|}{ Reporting city: } \\
\hline Amsterdam & $66 \cdot 3$ & $26 \cdot 8$ & $42 \cdot 8$ & $56 \cdot 0$ \\
\hline The Hague & $12 \cdot 7$ & $38 \cdot 2$ & $30 \cdot 6$ & $31 \cdot 9$ \\
\hline Rotterdam & $21 \cdot 3$ & $35 \cdot 0$ & $27 \cdot 2$ & $12 \cdot 1$ \\
\hline \multicolumn{5}{|l|}{ Sex: } \\
\hline Male & $73 \cdot 8$ & $82 \cdot 7$ & $78 \cdot 8$ & $73 \cdot 6$ \\
\hline Female & $24 \cdot 6$ & $15 \cdot 9$ & $20 \cdot 4$ & $26 \cdot 4$ \\
\hline Unknown & 1.6 & $1 \cdot 4$ & 0.8 & 0.0 \\
\hline \multicolumn{5}{|l|}{ Age (years): } \\
\hline$<20$ & $10 \cdot 7$ & $6 \cdot 8$ & $6 \cdot 9$ & $5 \cdot 5$ \\
\hline $20-24$ & $24 \cdot 6$ & $22 \cdot 3$ & $29 \cdot 9$ & $19 \cdot 8$ \\
\hline $25-29$ & $24 \cdot 2$ & $28 \cdot 2$ & $29 \cdot 6$ & $27 \cdot 5$ \\
\hline $30-34$ & $16 \cdot 3$ & $14 \cdot 1$ & $14 \cdot 2$ & $22 \cdot 0$ \\
\hline $35-39$ & $8 \cdot 7$ & $9 \cdot 5$ & $8 \cdot \overline{8}$ & $11 \cdot 0$ \\
\hline$>=40$ & $12 \cdot 7$ & $18 \cdot 2$ & $10 \cdot 6$ & $14 \cdot 3$ \\
\hline Unknown & $2 \cdot 8$ & 0.5 & & \\
\hline \multicolumn{5}{|l|}{ Nationality: } \\
\hline Dutch & $29 \cdot 8$ & $25 \cdot 5$ & $24 \cdot 0$ & $18 \cdot 7$ \\
\hline Turkish & 23.0 & $26 \cdot 8$ & $22 \cdot 3$ & $19 \cdot 8$ \\
\hline Moroccan & $6 \cdot 7$ & $5 \cdot 5$ & $6 \cdot 8$ & $8 \cdot 8$ \\
\hline Surinam/Antilles & $6 \cdot 7$ & $5 \cdot 0$ & $8 \cdot 5$ & $11 \cdot 0$ \\
\hline Latin American & $6 \cdot 7$ & $4 \cdot 1$ & $5 \cdot 0$ & $11 \cdot 0$ \\
\hline Other & $22 \cdot 6$ & $25 \cdot 9$ & $16 \cdot 2$ & $18 \cdot 7$ \\
\hline Unknown & $4 \cdot 4$ & $7 \cdot 3$ & $17 \cdot 2$ & $12 \cdot 1$ \\
\hline \multicolumn{5}{|l|}{ Commercial sex: } \\
\hline Yes & & $46 \cdot 4$ & $33 \cdot 0$ & $39 \cdot 6$ \\
\hline No & 34.5 & $16 \cdot 8$ & $37 \cdot 8$ & $39 \cdot 6$ \\
\hline Unknown & $28 \cdot 2$ & $36 \cdot 8$ & $29 \cdot 3$ & $20 \cdot 9$ \\
\hline
\end{tabular}

Table 4 Adjusted odds ratios (with 95\% CI) for the association between statistically significant variables and TRNG/PPNG infections in men in 1989 and $1990(n=368$, 557 , respectively)

\begin{tabular}{|c|c|c|}
\hline & 1989 & 1990 \\
\hline & OR $(95 \% \mathrm{CI})$ & OR $(95 \% \mathrm{CI})$ \\
\hline \\
\hline $\begin{array}{l}\text { Yes }(n=176204) \\
\text { Unknown }(n=93138)\end{array}$ & $2 \cdot 3(1 \cdot 3-4 \cdot 1)$ & $1 \cdot 2(0 \cdot 7-2 \cdot 1)$ \\
\hline \multirow{2}{*}{\multicolumn{3}{|c|}{ Age $(\operatorname{ref} 20-29$ years $(n=183313))$ : }} \\
\hline$<20$ years $(n=2937)$ & & \\
\hline $30-39$ years $(n=90138)$ & $\begin{array}{l}0.0(0 \cdot 2-1 \cdot 4) \\
1 \cdot 3(0 \cdot 7-2 \cdot 3)\end{array}$ & $\begin{array}{l}1 \cdot 2(0 \cdot 4-3 \cdot 6) \\
1.8(1 \cdot 0-3 \cdot 2)\end{array}$ \\
\hline$>=40$ years $(n=6669)$ & $1 \cdot 1(0 \cdot 6-2 \cdot 1)$ & $1.6(0.7-3.4)$ \\
\hline \multicolumn{3}{|l|}{ Reporting city (ref Amsterdam $(n=174235)$ ): } \\
\hline The Hague $(n=92180)$ & $7 \cdot 7(4 \cdot 0-15 \cdot 2)$ & $0.9(0.5-1 \cdot 6)$ \\
\hline Rotterdam $(\mathrm{n}=102142)$ & $4 \cdot 3(2 \cdot 4-7 \cdot 6)$ & $0.3(0 \cdot 1-0.8)$ \\
\hline
\end{tabular}

Model 1989: $-2 \log$ likelihood, $\chi^{2}=76 \cdot 1, \mathrm{df}=7, \mathrm{p}=0.0001$, adjusted $\mathrm{OR}$ is adjusted for all variables in the model.

Model 1990: $-2 \log$ likelihood, $\chi^{2}=19 \cdot 7, \mathrm{df}=7, \mathrm{p}=0 \cdot 0062$, adjusted $\mathrm{OR}$ is adjusted for all variables in the model.

Table 5 Adjusted odds ratios for the association between statistically significant variables and TRNG/PPNG infections in women in 1989 and $1990(n=248)$

\begin{tabular}{ll} 
& OR $(95 \% \mathrm{CI})$ \\
\hline Nationality (ref Netherlands $(\mathrm{n}=71)):$ & \\
Turkish $(\mathrm{n}=12)$ & $8 \cdot 2(1 \cdot 9-34 \cdot 8)$ \\
Moroccan $(\mathrm{n}=7)$ & $1 \cdot 4(0 \cdot 1-14 \cdot 2)$ \\
Surinam/Antilles $(\mathrm{n}=17)$ & $2 \cdot 3(0 \cdot 6-9 \cdot 4)$ \\
Latin America $(\mathrm{n}=55)$ & $3 \cdot 4(1 \cdot 2-9 \cdot 3)$ \\
Other/unknown $(\mathrm{n}=86)$ & $2 \cdot 2(0 \cdot 8-5 \cdot 3)$ \\
Age (ref $20-24$ years $(\mathrm{n}=67)):$ & $1 \cdot 3(0 \cdot 4-5 \cdot 1)$ \\
$<20$ years $(\mathrm{n}=24)$ & $1.9(0 \cdot 8-4 \cdot 7)$ \\
$25-29$ years $(\mathrm{n}=76)$ & $1 \cdot 8(0 \cdot 6-5 \cdot 2)$ \\
$30-34$ years $(\mathrm{n}=38)$ & $1 \cdot 9(0 \cdot 5-7 \cdot 4)$ \\
$35-39$ years $(\mathrm{n}=20)$ & $6 \cdot 2(1 \cdot 9-19 \cdot 7)$ \\
$>=40$ years $(\mathrm{n}=23)$ & $3 \cdot 1(1 \cdot 4-6 \cdot 8)$ \\
Reporting city $(\mathrm{ref}$ Amsterdam $(\mathrm{n}=126)):$ & $1 \cdot 9(0 \cdot 8-4 \cdot 5)$ \\
The Hague $(\mathrm{n}=59)$ & $\mathrm{n}=63)$ \\
Rotterdam $(\mathrm{n}=63)$ & \\
\hline
\end{tabular}

Model: $-2 \log$ likelihood $\chi^{2}=30 \cdot 1, \mathrm{df}=12, \mathrm{p}=0.0027$, adjusted $\mathrm{OR}$ is adjusted for all variables in the model.
Correlates of TRNG/PPNG infection

As the prevalence of TRNG/PPNG was different for 1989 and 1990 the logistic regression analyses were carried out separately for both years. Commercial sex contacts were independently associated with TRNG/PPNG infection for men in 1989 but not in 1990 (table 4). Also it was shown that in 1989 PPNG from The Hague and Rotterdam was more often TRNG than PPNG from Amsterdam. In combined multivariate analyses for 1989 and 1990 it was shown that commercial sex contacts in The Hague and Rotterdam increased the risk of acquisition of TRNG/PPNG with OR = 4.9 and $3 \cdot 1$, respectively; this association was not found for Amsterdam (data not in table 4). Also age was significantly associated with TRNG in the combined analyses $\left(\mathrm{OR}_{>40 \mathrm{yrs}}=\right.$ $1 \cdot 6$; $95 \%$ CI $1 \cdot 1-2 \cdot 5)$. For women, only combined analyses could be presented owing to power problems for 1990: independent correlates included a Latin American (mainly Colombia and Dominican Republic) or Turkish nationality and age 40 years or older. In addition, PPNG isolates from The Hague were more often TRNG compared with Amsterdam after adjusting for the other variables (table 5). For women, the association between TRNG/PPNG and commercial sex work could not be studied as $50 \%$ of the data were missing; an association with commercial sex work was found univariately but was not significant $\left(\mathrm{OR}_{1989}=1 \cdot 9 ; 95 \% \mathrm{CI} 0 \cdot 5-6 \cdot 7\right)$.

\section{Discussion}

GONORRHOEA INCIDENCE RATES

The incidence of gonorrhoea decreased dramatically in the past decade but now appears to stabilise. The reduction in the incidence of gonorrhoea has been seen in many countries over the past $10-15$ years. This decline could be due to the implementation of control programmes in the late 1970 s and behavioural changes as a result of the AIDS epidemic, although the incidence rates were already declining before the awareness of AIDS. ${ }^{28}$ The rates for decline differ for gonorrhoea and PPNG (suggesting opposite trends) which may be explained by different determinants of transmission. PPNG are rarely diagnosed in homosexual men suggesting that these infections are mainly spread in the heterosexual populations. ${ }^{419}$ 29-32 The drop in incidence rates started earlier in homosexual men, accounting partly for the sharp decrease in 1984-6 whereas the decline among heterosexuals started later (in 1987).$^{28}$ It has been suggested that gonorrhoea can be maintained at low levels in communities largely through sustained hyperendemic transmission in high risk core populations. ${ }^{19}$ 31-34 This may account for the present low (but stable) endemicity of gonorrhoea.

mental commercial sex contacts were repc more often $(53 \%)$ in the first three quarters of 1989 then in the five consecutive quarters (38\%). Turkish men reported more commercial sex contacts $(62 \%)$ than Dutch men (29\%) but no difference was found between TRNG/PPNG and non-TRNG/PPNG (not in table 3).

\section{PREVALENCE OF PPNG AND TRNG}

In the past decade, the PPNG prevalence (as the number of PPNG among the total number of gonococcal isolates) increased consistently. The epidemiological pattern of PPNG seen in 
the Netherlands is similar to that reported in other countries. ${ }^{35-38}$ Assuming that the core group theory also applies to PPNG, ${ }^{31}$ the infection is maintained in the community by a small group of high risk individuals. Since its emergence, TRNG has become prevalent in various populations in many countries. ${ }^{710153539-44}$ In the United Kingdom in 1988 only eight of $1500(0.5 \%)$ gonococcal isolates were tetracycline resistant ${ }^{40}$; in the Netherlands already $9 \%$ of all PPNG and 5\% of non-PPNG was TRNG. ${ }^{14}$ Between 1988 and 1995, the TRNG/PPNG in the United Kingdom increased in frequency to (an estimated) $50 \%$ of PPNG isolates. ${ }^{45}$ In 1992, 42 of 378 isolates $(11 \%)$ were TRNG at a genitourinary medicine clinic in London. ${ }^{15}$ In France and Denmark the first TRNG infection was found in $1989^{38} 39$ and in Spain in $1990 .{ }^{42}$ The French strain resembled the Dutch strain that was highly prevalent during the microepidemic of TRNG/PPNG (NR/IB6). ${ }^{39}$ Importation from the Netherlands was therefore suggested. In $1994,8 \cdot 2 \%$ of the isolates from the national Gonococcal Isolate Surveillance Project (GISP, US) were TRNG, of which $1 \cdot 7 \%$ were TRNG/PPNG (CDC, unpublished data).

\section{CORRELATES OF TRNG/PPNG INFECTION}

The epidemic increase of TRNG/PPNG infections in 1989 could only be investigated with a retrospective case note review. Most probably, the introduction of TRNG/PPNG took place in The Hague in 1988/1989. Surveillance data revealed that in the first half of $198829 \%$ of PPNG isolates from The Hague were also tetracycline resistant whereas none of the PPNG in Rotterdam or Amsterdam were; for the second half of 1988 these figures were $59 \%, 25 \%$, and $2 \%$, respectively. ${ }^{46}$ Because only incomplete information was available on recent travel outside of the Netherlands, it could not be confirmed or be ruled out that importation contributed to the emergence of plasmid mediated resistance to tetracycline. There is strong evidence that commercial sex was a major contributor to the spread and establishment of TRNG/PPNG in the community (especially in The Hague and Rotterdam). Although for women the association could not be studied, there is indirect evidence that commercial sex work played a role-for example, the independent association of TRNG/PPNG with certain ethnic groups. These subgroups, including women from Latin America who work as prostitutes (as window prostitutes in $A m s t e r d a m^{30}$ ), are known to contribute in the spread of STD. ${ }^{30} 3247$ We therefore conclude that high frequency transmitters, like prostitutes and their clients, played an important role in the spread of TRNG/PPNG in the community.

\section{AUXOTYPE/SEROVAR CLASSES}

The microbiological typing scheme has proved to be a useful tool in studying epidemic increases. $^{51948}$ The serogroup IB was most common among the Dutch isolates, with the A/S classes NR/IB-1 and NR/IB-3 persisting throughout. The distribution of $\mathrm{A} / \mathrm{S}$ classes among PPNG is quite different from that in United Kingdom (London hospital) isolates. ${ }^{49}$ In these latter isolates the serotypes IA-1/2, IA-4, IA-6, and IB-5/7 account for almost half of the PPNG isolates ${ }^{49}$ and were relatively uncommon in our isolates. The temporal distribution of the A/S classes show a heterogeneous mixture, in which certain $\mathrm{A} / \mathrm{S}$ classes appear, disappear, and re-emerge as was also demonstrated by others. ${ }^{26} 49$ The diversity in strains suggests a continuous (re-) introduction of new (resistant) strains.

The epidemic increase of TRNG/PPNG in the Netherlands was mainly caused by NR/IB6, PRO/IA-3, and PRO/IA-6, suggesting a clonal spread of a few strains. Unfortunately. genotyping data are not available to support or oppose this theory. Further spread of tetracycline resistance, due to the instability of the 25.2 MDa plasmid, which facilitates its own transfer to other (sensitive) organisms, was anticipated. ${ }^{17} 50$ In fact, in several countries other A/S classes were detected among TRNG that were uncommon among our isolates: NR/IB-2 accounted for $83 \%$ of the TRNG isolates in London in $1992^{15}$; isolates from the United States in 1985 comprised at least 19 A/S classes, of which PRO/IB-1 dominated $(54 \%)^{13}$; Canadian TRNG isolates in 1986-9 expressed PRO/IB-1 (33\%), PRO/IB-2 (27\%), Ornithine/IA-1/2 (15\%). ${ }^{50}$

ANTIBIOTIC RESISTANCE

Various factors are involved with the emergence and spread of antibiotic resistance in gonococci. Resistance was often associated with the importation of new strains and further spread and establishment in the community through transmission in high risk individuals. ${ }^{19} 203133363940485152$ There is evidence that these factors may be of major importance for the introduction and early spread of infection but are less important for spread at an endemic level ${ }^{20}{ }^{33}$ although it has been suggested that prostitution remains important for further spread of resistance. ${ }^{30}$ Treatment regimens for gonorrhoea are important as antimicrobials may favour certain resistant strains through selective pressure ${ }^{1353-56}$; also there is evidence that noncompliance and self administered antibiotic treatment may facilitate the development of resistance. ${ }^{19} 20335357$ Tetracycline has not been used as a sole therapy for gonorrhoea in the Netherlands, hence no selective pressure could be expected. However, the treatment of common coinfections with $C$ trachomatis (with tetracycline) could have affected the spread of TRNG.

Antimicrobial resistance shows wide geographical variation. Surveillance data from local, national, and international levels are needed to guide the clinician in the choice of treatment; therapy is often initiated on basis of clinical presentation without prior knowledge of the antimicrobial sensitivity of $N$ gonorrhoeae in the individual. At present, no resistance to currently used antibiotics was observed in the Netherlands except for one 
strain resistant for ciprofloxacin. Importantly, our surveillance data show that PPNG strains are less sensitive to other clinically relevant antibiotics than non-PPNG; this trend was also reported by the GISP study group. ${ }^{58}$ Resistance to fluoroquinolones or cephalosporins can be expected to develop and could emerge first on these strains. ${ }^{58}$ Until 1992, most isolates tested in GISP have been susceptible for ciprofloxacin. ${ }^{1058}$ In 1992 and 1993, decreased susceptibilities (MICs $\geqslant 0.125 \mathrm{mg} / \mathrm{l}$ ) were detected..$^{58}$ Recently, several reports have been published on clinically important resistance to fluoroquinolones in South East Asia, the United States, ${ }^{59-61}$ and Europe, ${ }^{62-66}$ on reduced susceptibility to fluoroquinolones in the United Kingdom, United States, Canada, Australia, and South East Asia $^{67-72}$ and on resistance to spectinomycin in Korea. ${ }^{56}$ Also reduced sensitivity to cephalosporins was reported. ${ }^{6}{ }^{73}$ Presumably, it is not a question of whether they will become resistant but when they will become resistant. To limit selection pressure for the development of microbial resistance to third generation cephalosporins, the use of oral cephalosporins (which will inevitably support self medication) should be discouraged.

\section{Conclusion}

Because of the continuing threat of developing resistance and the instability of microbiological characteristics of gonococci a continuous national surveillance is necessary. A programme should include:

- limited information on gonorrhoea patients to obtain an insight into the determinants for infection with resistant gonococci. The survey on TRNG/PPNG has shown that background information is needed to indicate the potential source and to identify the groups at risk. Control measures should include rapid detection, information on possible source of infection, recent travel, increased awareness, and appropriate therapy for specific groups at risk.

- controlling of PPNG remains important because of reduced sensitivity for other antimicrobials: rapid treatment, contact tracing, specific prevention programmes for high risk individuals.

- monitoring resistance to cephalosporins and fluoroquinolones: strains with decreased susceptibility were detected in the Netherlands; there is a threat of importation and subsequent further spread from other countries (Japan, South East Asia) where the prevalence of resistance is high and rapidly increasing.

- preventing further spread of strains with reduced susceptibility to these antibiotics; therefore, both local and national level surveillance is needed (establish treatment guidelines based on resistance patterns).

The authors acknowledge the cooperation of the participating laborates in the PPNG surveillance, laboratories in Amsterdam, The Ham. The J A R van den Hoek for critical comments on previous drafts of this manuscript.
1 Martin JE, Lester A, Price EV, Schmale JD. Comparative study of gonococcal susceptibility to penicillin in the United States, 1955-1969. F Infect Dis 1970;122:459-61.

2 Philips I. Beta-lactamase producing, penicillin-resistant gonococcus. Lancet 1976;2:656-7.

3 Ashford WA, Golash RG, Hemming VG. Penicillinase-producing Neisseria gonorrhoeae. Lancet 1976;2:657-8.

4 Jaffe HW, Biddle JW, Johnson SR, Wiesner PJ. Infections due to penicillinase-producing Neisseria gonorrhoeae in the

Faruki H, Kohmescher RN, McKinney WP, Sparling PF A community-based outbreak of infection with penicillinase-resistant Neisseria gonorrhoeae not producing penicil- $\mathbb{D}$ linase (chromosomally mediated resistance). $N$ Engl $f$ Med 1985;313:607-11.

6 Rice RJ, Biddle JW, JeanLouis JA, DeWitt WE, Blount JH, $\stackrel{\vec{\sigma}}{\vec{\sigma}}$ Morse SA. Chromosomally mediated resistance in Neisseria gonorrhoeae in the United States: results of surveillance and reporting, 1983-1984. F Infect Dis 1986;53: 340-5.

7 Centers for Disease Control. Sentinel surveillance system for antimicrobial resistance in clinical isolates of Neisseria gonorrhoeae. MMWR 1987;36:585-6, 591-3.

8 Centers for Disease Control. Antibiotic-resistant strains of Neisseria gonorrhoeae. Policy guidelines for detection, $\vec{O}$ management and control. MMWR 1987;36(suppl 5S): managem.

9 Centers for Disease Control. 1985 STD treatment guidelines. $M M W R$ 1985;34(suppl 4S):83S-86S, 92S-94S.

10 Schwarcz SK, Zenilman JM, Schnell D, Knapp JS, Hook EW 3d, Thompson S, et al. National surveillance of $\omega$ antimicrobial resistance in Neisseria gonorrhoeae. $\not A M A$ 1990;264:1413-7.

11 Centers for Disease Control. 1993 STD treatment guidelines. $M M W R$ 1993;42(RR-14):4-5.

12 Centers for Disease Control. Tetracycline-resistant $ᄋ$ Neisseria gonorrhoeae-Georgia, Pennsylvania, New Hampshire. MMWR 1985;34:563-4, 569-70.

13 Knapp JS, Zenilman JM, Biddle JW, Perkins GH, DeWitt WE, Thomas ML, et al. Frequency and distribution in $\mathbb{D}$ the United States of strains of Neisseria gonorrhoeae with $\varnothing$ plasmid-mediated high-level resistance to tetracycline. $\mathcal{f} \frac{\mathcal{D}}{\mathcal{O}}$ Infect Dis 1987;155:819-22.

14 Klingeren $B$ van, Dessens-Kroon $M$, Verheuvel $M$. 음 Increased tetracycline resistance in gonococci in the Netherlands. Lancet 1989;ii:1278.

15 Lewis DA, Ison CA, Forster GE, Goh BT. Tetracyclineresistant Neisseria gonorrhoeae. Characteristics of patients and isolates at a London genitourinary medicine clinic. Sex Transm Dis 1996;23:378-83.

16 Roberts MC, Wagenvoort JHT, van Klingeren B, Knapp JS. TetM and B-lactamase containing Neisseria gonorrhoeae (tetracycline resistant and penicillinase producing) in the Netherlands. Antimicrob Agents Chemother 1988; in the 158 .

17 Morse SA, Johnson SR, Biddle JW, Roberts MC. Highlevel tetracycline-resistance in Neisseria gonorrhoeae is due to the acquisition of the streptococcal tetM determinant. Antimicrob Agents Chemother 1986;30:664-70.

18 Gascoyne DM, Heritage J, Hawkey PM, Turner A, van Klingeren B. Molecular evolution of tetracycline-resistance plasmids carrying TetM found in Neisseria gonorrhoeae from different countries. I Antimicrob Chemother 1991;28:173-83.

19 Handsfield $\mathrm{HH}$, Rice RJ, Roberts MC, Holmes KK. Localized outbreak of penicillinase-producing Neisseria gonorrhoeae; paradigm for introduction and spread of 3 gonorrhoeae; paradigm for introduction and spread

20 Hook EW 3d, Brady WE, Reichart CA, Upchurch DM, 을 Sherman LA, Wasserheit JN. Determinants of emergence of antibiotic-resistant Neisseria gonorrhoeae. F Infect Dis 1989;159:900-7.

21 Klingeren B van, Wijngaarden LJ van, Dessens-Kroon $M, N$ Embden JDA van. Penicillinase-producing gonococci in the Netherlands in 1981. F Antimicrob Chemother 1983; 11:15-20.

22 van Klingeren B, Ansink-Schipper MC, Doornbos L, Cு Lampe AS, Waagenvoort JH, Dessens-Kroon $M$, et al. Surveillance of antibiotic susceptibility of non-penicillinase producing Neisseria gonorrhoeae in the Netherlands from 1983 to 1986. F Antimicrob Chemother 1988;21: 737-44.

23 Hendry AT, Stewart TO. Auxanographic grouping and typing of Neisseria gonorrhoeae. Can $\mathcal{f}$ Microbiol 1979;25: 512-21.

24 Ansink-Schipper MC, Huikeshoven MH, Woudstra RK, van Klingeren $\mathrm{B}$, de Koning GA, Tio $\mathrm{D}$, et al. Epidemiology of penicillanse producing $N$. gonorrhoeae in

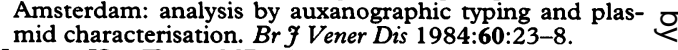

25 Knapp JS, Tam MR, Nowinski RC, Holmes KK, 尺 Sandstrom EG. Serological classification of Neisseria gonorrhoeae with use of monoclonal antibodies to gonococcal outermembrane protein I. F Infect Dis 1984;150:44-8.

26 Knapp JS, Holmes KK, Bonin P, Hook EW. Epidemiology of gonorrhea: distribution and temporal changes in auxotype/serovar classes of Neisseria gonorrhoeae. Sex Transm Dis 1987;14:26-32.

27 Duynhoven YTHP van, Laar MJW van de, Dessens-Kroon $M$, Verheuvel $M$, Klingeren $B$ van. Epidemie van penicillinase-vormende en tevens tetracycline-resistente gonokokken; risicofactoren voor de verspreiding. Ned Tijdschr Geneeskd 1995;139:283-8. (in Dutch)

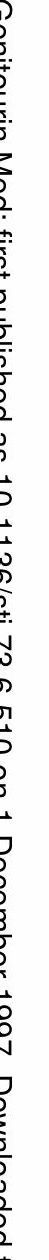


28 Laar MJW van de, Pickering J, Hoek JAR van den, Griensven GJP van, Coutinho RA, Water HPA van de. Declining gonorrhoea rates in The Netherlands, 1976-1988: consequences for the AIDS epidemic Genitourin Med 1990:66:148-55. 29 Hill J, Witte J, Wroten J, et al. Penicillinase-producing
Neisseria gonorrhoeae-United States, 1986. MMWR 1987;36:107-8.

30 Prins $M$, Bindels PJE, Coutinho RA, Henquet CJM, Doornum GJJ van, Hoek JAR van den. Determinants of penicillinase producing Neisseria gonorrhoeae infections in peterosexuals in Amsterdam. Genitourin Med 1994;70: 247-52.

31 Rothenberg R, Voigt R. Epidemiologic aspects of control of penicillinase-producing Neisseria gonorrhoeae. Sex Transm Dis 1988;15:211-6.

32 Laar MJW van de, Sleutjes MPM, Postema CA, Water HPA van de. Seksueel overdraagbare aandoeningen bi allochtone bevolkingsgroepen; een oriënterend onderzoek. (in Dutch) Ned Tijdschr Geneeskd 1991;15:1542-7.

33 Zenilman JM, Bonner M, Sharp KL, Rabb JA, Alexander ER. Penicillinase-producing Neisseria gonorrhoeae in Dade County, Florida: evidence of core-group transmitters and the impact of illicit antibiotics. Sex Transm Dis the impact of

34 Hethcote HW, Yorke JA. Gonorrhoea transmission dynamics and control. Lecture notes in biomathematics, No 56 ics and control. Lecture notes

35 Division of STD Prevention. Sexually Transmitted Disease Surveillance, 1994. US Department of Health and Human Services, Public Health Service. Centers for Disease Control and Prevention. Atlanta, Septembe 1995.

36 Ringuet J, Noel L. Penicillinase-producing Neisseria gonorrhoeae infections in Quebec: an assessment of the situation to the end of 1988. Canada Diseases Weekly Repor 1990;16:49-52.

37 Issack MI, French GL, O'Farrel N. Continuing high prevalence of penicillinase-producing Neisseria gonorrhoeae at central London hospital. Genitourin Med 1995;71:265.

38 Reimann K, Bollerup AC, Lind I. The emergence of penicillinase-producing Neisseria gonorrhoeae strains carrying the $4.9 \mathrm{~kb}$ (Toronto) plasmid in Denmark and of a nove large plasmid in two nonpenicillinase-producing Neisseri gonorrhoeae strains. Sex Transm Dis 1992;19:206-12.

39 Casin I, Perenet F, Issoire C, Riou JY, Morel P, Perol Y. High-level tetracycline resistance in penicillinase-producing Neisseria gonorrhoeae in France. Eur $\mathcal{F}$ Clin Microbio Infect Dis 1989;8:929-31.

40 Ison CA, Terry $P$, Blindayna $K$, Gill MJ, Adams J, Woodford N. Tetracycline-resistant gonococci in UK. Woodford N. Tetracyct
Lancet 1988;1:651-2.

41 Waugh MA, Lacey CJN, Hawkey PM, Heritage J, Turner A, Jephcott AE. Spread of Neisseria gonorrhoeae resistant to tetracycline outside the United States of America. $B M F$ 1988;296:898.

42 Vazquez JA, Berron S, Menendez B. Isolate of Tet M-containing Neisseria gonorrhoeae (TRNG) in Spain Genitourin Med 1990;66:303-4

43 Carballo M, Pauze M, Dillon JR. Increase of Neisseria gonorrhoeae isolates with combined plasmid-mediated resistance to tetracycline (TRNG) and penicillin (PPNG). Canada Diseases Weekly Report 1990;16:219-22.

44 Brett MSY, Davies HGD, Blockley JR, Heffernan HM. Antibiotic susceptibilities, serotypes and auxotypes of Neisseria gonorrhoeae isolated in New Zealand. Genitourin Med 1992;68:321-4.

45 Communicable Diseases Surveillance Center. Sexually transmitted diseases quarterly reports: gonorrhoea in England and Wales. Communicable Diseases Report 1996 6:110-1.

46 Klingeren B van, Dessens-Kroon $M$, Verheuvel $M$ Surveillance van penicillinase vormende gonokokken in Nederland; incidentie en prevalentie in 1988. RIVM rapport 358004009 , Bilthoven, 1989. (in Dutch)

47 Haastrecht HJA van, Fennema JSA, Coutinho RA, Helm TCM van der, Kint JAPCM, Hoek JAR van den. HIV prevalence and risk behaviour among prostitutes and prevalence and risk behaviour among prostitutes and
clients in Amsterdam: migrants at increased risk for HIV clients in Amsterdam: migrants at increas

48 Centers for Disease Control. Multiple strain outbreak of penicillinase-producing Neisseria gonorrhoeae-Denver Colorado, 1986. MMWR 1986;36:534-43.

49 Warren C, Phillips I. Penicillinase producing Neisseria gonorrhoeae from St Thomas's hospital 1976-1990, the firs 15 years. Genitourin Med 1993;69:201-7.

50 Dillon JR, Carballo M. Molecular epidemiology and novel combinations of auxotype, serovar, and plasmid content in tetracycline-resistant Neisseria gonorrhoeae isolated in Canada. Can 7 Microbiol 1990;36:64-7.
51 Bethea RP, Muth SQ, Potterat JJ, Woodhouse DE, Muth JB. Gang-related outbreak of penicillinase-producing Neisseria gonorrhoeae and other sexually transmitted diseases-Colorado Springs, Colorado, 1989-1991. $M M W R$ 1993;42:25-8.

52 Bygdeman SM, Ruden AK, Jonsson A, Lidbrink P, Olofsson MB, Backman M, et al. Antibiotic susceptibility, serovars and auxotypes of gonococcal isolates in Stockholm. Relation to geographical origin of the infection. Int $\mathcal{F}$ STD AIDS 1993;4:33-40.

53 Reichart CA, Neumann T, Foreman P, Zenilman JM, Hook EW 3d. Temporal trends in gonococcal antibiotic resistance in Baltimore. Sex Transm Dis 1992;19:213-8.

54 Lind L. Epidemiology of antibiotic resistant Neisseria gonorrhoeae in industrialized and developing countries. Scand $\mathcal{F}$ Infect Dis 1990;69:77-82.

55 Telzak EE, Spitalny KC, Faur YC, Knapp JS, Gunn RA, Blum $S$, et al. Risk factors for infection with plasmidmediated high-level tetracycline resistant Neisseria gonorrhoeae. Sex Transm Dis 1989;16:132-6.

56 Boslego JW, Tramont EC, Takafuji ET, Diniega BM, Mitchell BS, Small JW, et al. Effect of spectinomycin use on the prevalence of spectinomycin-resistant and of penicillinase-producing Neisseria gonorrhoeae. $N$ Engl $\mathcal{F}$ Med 1987;317:272-8.

57 Jaffe HW, Zaidi AA, Thornsberry C, Reynolds GH, Wiesner PJ. Trends and seasonality of antibiotic resistance of Neisseria gonorrhoeae. F Infect Dis 1977;136: tance 68 .

58 Gorwitz RJ, Nakashima AK, Moran JS, Knapp JS. Sentinel surveillance to antimicrobial resistance in Neisseria gonorrhoeae, United States, 1988-1991. MMWR 1993;42(SS3):29-39.

59 Ohye R, Higa H, Vogt R, Washington JA, Doyle L, Sayers D, Halpin TJ. Decreased susceptibility of Neisseria gonorrhoeae to fluoroquinolon

60 Ehret J, Douglas JM, Judson FN, Hale J, Krekeler B, Handsfield $\mathrm{HH}$. Fluoroquinolone resistance in Neisseria Handsfield $\mathrm{HH}$. Fluoroquinolone resistance in Neisseria
gonorrhoeae-Colorado and Washingon, 1995. Arch gonorrhoeae-Colorado and
Dermatol 1995;131:1367-9.

61 Kam KM, Wong PW, Cheung MM, Ho NgKY, Lo KK. Quinolone-resistant Neisseria gonorrhoeae in Hong Kong. Sex Transm Dis 1996;23:103-8.

62 Jephcott AE, Turner A. Ciprofloxacin resistance in gonococci. Lancet 1990;335:165.

63 Gransden WR, Warren CA, Phillips I. 4-Quinolone-resistant Neisseria gonorrhoeae in the United Kingdom. $7 \mathrm{Med}$ Microbiol 1991;34:23-7.

64 Birley H, McDonald P, Fletcher J. High level ciprofloxacin resistance in Neisseria gonorrhoeae. Genitourin Med 1994; 70:292-3.

65 Thompson C, Young H, Moyes A. Ciprofloxacin resistant Neisseria gonorrhoeae. Genitourin Med 1995;71: 412-5.

66 Turner A, Gough KR, Jephcott AE, McClean AN. Importation into the UK of a strain of Neisseria gonorrhoeae resistant to penicillin, ciprofloxacin and tetracycline. Genitourin Med 1995;71:265-6.

67 Ison CA, Branley NS, Kirtland K, Easmon CSF. Surveillance of antibiotic resistance in clinical isolates of Neisseria gonorrhoeae. BMF 1991;303:1307.

68 Tapsall JW, Shultz TR, Phillips EA. Characteristics of Neisseria gonorrhoeae isolated in Australia showing decreased sensitivity to quinolone antibiotics. Pathology 1992;24:227-31.

69 Knapp JS, Washington JA, Doyle LJ, Neal SW, Parekh MC, Rice RJ. Persistence of Neisseria gonorrhoeae strains with decreased susceptibilities to ciprofloxacin and ofloxacin in Cleveland, Ohio, from 1992 through 1993. Antimicrob Agent Chemother 1994;38:2194-6.

70 Harnett N, Brown S, Riley G, Terro R, Krishnan C. Decreased susceptibility of Neisseria gonorrhoeae to fluoroquinolones, Ontario, 1992-1994. Canada Communicable Diseases Report 1995:17-20.

71 Kam KM, Lo KK, Ho Ng KY, Cheung MM. Rapid decline in penicillinase-producing Neisseria gonorrhoeae in decline in penicillinase-producing Neisseria gonorrhoeae in Hong Kong associated with emerging 4-fluor

72 Tanaka M, Kumazawa J, Matsumoto T, Kobayashi I. High prevalence of Neisseria gonorrhoeae strains with reduced susceptibility to fluoroquinolones in Japan. Genitourin Med 1994;70:90-3.

73 Ye S-Z. Survey on antibiotic sensitivity of Neisseria gonorrhoeae strains isolated in China, 1987-1992. Sex Transm Dis 1994;21:237-40.

74 Schwebke JR, Whittington W, Rice RJ, Handsfield $\mathbf{H H}$, Hale J, Holmes KK. Trends in the susceptibility of Neisseria gonorrhoeae to ceftriaxone from 1985 through 1991. Antimicrob Agents Chemother 1995;39:917-20. 